\title{
RETRACTED ARTICLE: Analyses of seeing measurements on optical astronomical site testing at Abune Yosef Mount, Ethiopia
}

\section{Dessalegn A. Mekuriaw ${ }^{1}$}

Received: 19 September 2018 / Accepted: 23 April 2019/Published online: 22 May 2019

(C) Springer Nature B.V. 2019

This article [1] has been retracted at the request of the author. After publication, it was brought to the author's attention that the appropriate permissions to publish the data were not sought. Concerns were also raised that the findings reported in this study may be unreliable due to incorrect methods for data collection. The data collection methods have since been revised by the investigators. As the data owners (Ethiopian Space Science Technology Institution, Amhara National Regional State, Mekelle University, Bahir Dar University, Gondar University, and Woldia University) did not approve the disclosure of the information contained in the article, it has been retracted and removed from the journal.

\section{References}

1. Mekuriaw, D.A. Exp Astron (2019). https://doi.org/10.1007/s10686-019-09628-w

Publisher's note Springer Nature remains neutral with regard to jurisdictional claims in published maps and institutional affiliations.

Dessalegn A. Mekuriaw

dessnayt@yahoo.com

1 Washera Geo-space Research Labratory, Department of Physics, Bahir Dar University, Bahir Dar, Ethiopia 